\title{
Con(textos), indecidíveis e brisuras: a desconstrução derridiana em associações ao feminino e à maternidade
}

\section{Con(text), undecidable and brisure: Derrida's deconstruction in associations to women and maternity}

\section{Con(texto), indecidibles y brisure: asociaciones del deconstrucción de Derrida al femenino y la maternidad}

\author{
Fabíola Langaro* \\ Universidade Federal de Santa Catarina - UFSC, Florianópolis, Santa Catarina, \\ Brasil
}

\section{Mériti de Souza**}

Universidade Federal de Santa Catarina - UFSC, Florianópolis, Santa Catarina, Brasil

\begin{abstract}
RESUMO
Este trabalho problematiza a experiência de mulheres-mães na relação construída com filhos e filhas a partir da elaboração subjetiva dos lugares sociais e sexuais, frente às normas calcadas na heteronormatividade e no binarismo. A estratégia da desconstrução foi utilizada na leitura das falastextos das mulheres-mães, buscando e apontando seu jogo de oposições, essências e hierarquias. Consideramos que o trabalho operado pela desconstrução nos (con)textos se confronta com a barreira posta pela metafísica da presença, explicitando o embate entre uma operação feminina e uma operação masculina. Este embate contínuo explicita, ainda, os indecidíveis e as brisuras e sustenta brechas para a construção de práticas que embaralham os limites que demarcam a norma.
\end{abstract}

Palavras-chave: desconstrução, Derrida, feminino, mulheres.

\section{ABSTRACT}

This paper discusses the experience of women-mothers in the relationship built with sons and daughters from the subjective approach of the social/sexual places front the norms based on heteronormativity and on the binary. The strategy of deconstruction was used in the reading of the speech-texts of women-mothers, looking and pointing its play of oppositions, essences and hierarchies. We believe that the work operated by deconstructing into the con(texts) confronts the barrier posed by the metaphysics of presence, highlighting the clash between a female and a male operation. This ongoing clash explicit, yet the undecidable and brisures and sustains loopholes for building practices that shuffle the boundaries that demarcate the norm.

Keywords: deconstruction, Derrida, feminine, women. 


\begin{abstract}
RESUMEN
Este artículo discute las experiências de mujeres-madres em la relación construída com los hijos e hijas em la elaboración subjetiva de lugares sociales y sexuales delante las normas de la heteronormatividad y el binario. La estrategia de deconstrucción fué utilizada para ler el discursos-textos de mujeres-madres, mirando y señalan su juego de oposiciones, esencias y jerarquías. Creemos que el trabajo operado por la deconstrucción en (con)textos se enfrenta a la barrera que suponela metafísica de la presencia, destacando el choque entre una operación femenina y una operación masculina. Esta lucha en curso explica también lo indecidible y brisuras y mantiene lagunas para la construcción de prácticas que barajan los límites que demarcan la norma.
\end{abstract}

Palabras clave: La deconstrucción, Derrida, femenina, mujeres.

\title{
1 Introdução
}

Nas últimas décadas ampliaram-se as críticas e os debates referentes às normatizações sociais associadas às denominadas diferenças sexuais. Este trajeto histórico estaria permitindo, na contemporaneidade, a existência de maiores possibilidades sociais e subjetivas postas para as pessoas, visto que, em conjunto com alterações nos contextos econômicos e culturais, os movimentos feministas concentraram forças na luta contra a discriminação, contra as hierarquias e as relações de poder estabelecidas histórica e culturalmente.

Neste trabalho interessa problematizar a questão da inserção de mulheres-mães em um tempo, cultura e sociedade, marcados por questionamentos sobre a ordem social acerca dos lugares e mitos do feminino, considerando as possibilidades de constituição de si e de outros na perspectiva do feminino e do masculino.

A partir dessa problematização perguntamos: por que mulheres? Não se trata aqui de trabalhar com mulheres no universal, pois, não existe a mulher como uma categoria única. Trata-se de problematizar - movimento produzido por uma parcela de pessoas que se reconhecem e se denominam mulheres e estabelecem relações a partir dos padrões de masculino e de feminino conforme presentes na sociedade ocidental. Trabalha-se com a referência mulheres, já que em sua maioria os conceitos disponibilizados pela rede cultural encontram-se associados ao binarismo e ao referencial identitário. Porém, não se reitera a concepção de uma mulher marcada por uma essência e por um universal. Antes, se entende tratar-se de uma pessoa que se reconhece e se apresenta a partir da referência "mulher".

Por que mulheres-mães? De forma semelhante à grafia "mulheres", o termo "mãe" não implica em uma categoria única, mas pretende se referir aquelas pessoas que se reconhecem como mulheres e exercem 
a maternidade, incluindo aqui tanto aquelas que geraram seus filhos quanto aquelas que optaram pela adoção. Entretanto, em decorrência da dificuldade de lidar com os conceitos disponíveis na linguagem usual, doravante fala-se em mulheres-mães, entendendo esses conceitos segundo a leitura apresentada acima. Assim, trabalhar com mulheres-mães e privilegiar a relação entre elas e seus filhos e filhas, diz respeito à compreensão de que no momento em que se relacionam com seus filhos e filhas as mulheres-mães se deparam, de forma privilegiada e urgente, com a necessidade de serem coautoras na construção psíquica de outras pessoas. Nesta situação, entram em contato com a subjetividade que elaboraram/elaboram para si mesmas, no que tange o masculino e o feminino, e participam das configurações subjetivas que serão engendradas e possibilitadas para seus filhos e filhas. Isto porque os sujeitos encontram-se inseridos em sistemas de poder que regulam as práticas e as formas pelas quais podem e devem se reconhecer como sexuados (Foucault, 1993). Também, os sujeitos se vêem impelidos a elaborar uma possível coerência entre sexo, gênero, prazeres e desejos, respondendo às demandas sociais, jurídicas e da medicina sobre a construção de um gênero inteligível (Butler, 1999; 2008).

E por que "masculino" e "feminino"? Porque, ao enunciar estes conceitos, parte-se da compreensão crítica sobre as "identidades de gênero", no sentido de entendê-las como elaborações psíquicas que as pessoas constroem sobre si e que apresentam aspectos de ficção e de narrativa, mas também um aspecto de ação sobre a realidade. Em outras palavras, as diferenças sexuais podem ser compreendidas enquanto performatividades normativas inscritas nos corpos como verdades biológicas (Preciado, 2002, 2003).

O discurso que cada um de nós constrói a seu respeito e que procura manter a representação unitária e linear sobre a subjetividade aparece como uma identidade de gênero, sendo ficcional, porém, mobilizando para a ação (Freire Costa, 1986). Nesse sentido, considera-se, conforme afirma Rodrigues (2005, p. 2), que "a identidade não é algo dado, mas é efeito que se manifesta em um regime de diferenças, num jogo de referências", especificamente no caso das referências de masculino e feminino.

Com a referência ao falologocentrismo Derrida (2001; 2008; 2009) problematiza a predominância de uma determinada maneira de organização do conhecimento e da rede social que gira em torno do falo e do logos. Em outras palavras, esse movimento que predomina na sociedade ocidental recebe a denominação de falologocentrismo, pressupondo o falo e a razão como o ponto de referência a partir do qual ocorreria a modalização do conhecimento e a subjetividade, bem como, a produção do masculino e do feminino.

A partir destas considerações teóricas e da problematização apresentada acima foi delineada uma pesquisa calcada nos aportes 
derridianos da differánce, do falologocentrismo, da brisura, do indecidível, bem como, na desconstrução entendida como estratégia para a produção do conhecimento. Na pesquisa foi investigado como mulheres-mães elaboram sua relação com seus filhos e filhas na perspectiva do masculino e do feminino (Langaro, 2011). Informamos que para esta comunicação são apresentadas e trabalhadas as entrevistas com duas dessas mulheres-mães, que aqui receberam os nomes fictícios de Luiza e Aimê. Após a transcrição das falas, o material foi considerado como texto, conforme a perspectiva derridiana, e serviu como base para as reflexões aqui apresentadas. Em outras palavras, as entrevistas foram trabalhadas conforme a perspectiva teórica de Derrida e segundo a estratégia da desconstrução, sendo, dessa forma, consideradas como textos inseridos em um (con) texto social, político e linguístico.

Mais do que isso, as leituras dos (con)textos com base na différance mostra que o jogo de forças estabelecido entre o pensamento da metafísica da presença e o pensamento da desconstrução, desde que continuamente operante, abre espaços à construção de práticas que embaralhem os limites que demarcam o que é estar na norma ou fora dela, ampliando as possibilidades de experiências subjetivas.

$\mathrm{Na}$ desconstrução como estratégia de produção de conhecimento não há um fim almejado, em que se chegaria à solução de um impasse, gesto do qual Derrida quer afastar-se. Implica ainda não buscar uma interpretação, no sentido de que interpretar se liga à busca pela verdade e pela identidade do interpretado e do conceito (Continentino, 2006).

Se um texto é sempre heterogêneo, aberto, inacabado, não há necessidade de buscar nele conceitos que se repetem, nem uma interpretação que evidenciaria a origem e o sentido final e único dos mesmos. Isto porque Derrida (2001; 2008; 2009) questiona os limites da interpretação proposta pela filosofia apoiada na metafísica da presença, que supõe, em seu modo de fazer ciência, ser capaz de apropriar-se de uma verdade existente de maneira intrínseca ao seu objeto de estudo. O autor critica esta matriz filosófica que separa sujeito e objeto e que pressupõe que o sujeito seja capaz de ler uma verdade presente no objeto. Ele propõe uma atitude de alteridade radical com o texto, em que não há sentidos finais e únicos a serem revelados e assimilados, visto que qualquer significação está sempre por vir.

Espera-se com a leitura desconstrutora das entrevistas explicitar os pontos de aderência entre determinados sentidos e seus signos, bem como, problematizar os (con)textos que sustentam a manutenção dessas aderências entre sentidos e signos, simultaneamente ao trabalho de problematizar outros sentidos que deslizam nos textos das entrevistadas. 


\section{Uma leitura desconstrutora dos textos: estratégias para a produção do conhecimento em Derrida}

Derrida (2001; 2008) apresenta, na estratégia da desconstrução, aspectos que rompem com um enquadramento normativo de produção do conhecimento, entre eles a ênfase na historicidade dos conceitos; a dissimetria posta entre a palavra e a "coisa"; a quebra no paradigma da neutralidade na relação entre sujeito-objeto de pesquisa. Enfim, há a afirmação de que o caminho se constrói ao caminhar sendo produzido na interação da pesquisadora com aqueles que concordam em participar da caminhada conjunta que é a pesquisa.

No decorrer do seu trabalho Derrida apresenta os pressupostos orientadores da sua concepção de realidade, de conhecimento e de subjetividade, sustentando a desconstrução como estratégia para a produção do conhecimento e como meio de problematizar e analisar a realidade, o simbólico e seus embates. Assim, ele tanto problematiza o conceito hegemônico de método, considerando o atrelamento de um sentido único e metafísico a esse conceito, quanto problematiza os pressupostos de realidade, conhecimento e subjetividade, que 0 acompanham. Assim, para o autor a desconstrução opera como procedimento teórico e analítico para a produção do conhecimento (Derrida, 1991, 2001, 2008, 2009).

Nesta perspectiva, inicialmente foram realizadas entrevistas individuais com mulheres-mães, reconhecendo a dimensão interativa entre entrevistadora e entrevistada. Foram realizadas entrevistas com mulheres com idades entre 29 e 46 anos, que tinham pelo menos um filho e uma filha entre cinco e dezessete anos, contatadas por meio da estratégia da rede social, e que se dispuseram a participar da pesquisa. Todas as entrevistadas são brancas, moradoras de um bairro de classe média da cidade de Florianópolis, local onde a pesquisa foi realizada, sendo que quatro possuem formação em nível superior e uma finalizou o ensino médio. As mulheres participantes foram todas contatadas a partir da rede de relações da pesquisadora principal. Após o aceite inicial, foram agendadas entrevistas nos locais de preferência de cada participante. As entrevistadas assinaram o TCLE e a pesquisa obteve aprovação do Comitê de Ética da UFSC. As entrevistas acompanharam o movimento produzido pelas entrevistadas e entrevistadora e seguiram um roteiro mínimo com base em questões disparadoras na produção dos textos. Para o registro das informações, as entrevistas-textos foram gravadas e posteriormente transcritas, com o consentimento das participantes.

A fala das entrevistadas foi compreendida como texto, na medida em que se constituiu numa trama de diferenças, estando sempre inserida 
em um contexto, ou seja, implicada nas interseções que faz com os aspectos sociais, econômicos, históricos e culturais em que é produzida. Para Derrida (2008), o texto não se limita à escrita, mas se refere a um tecido, uma cadeia de signos na qual as diferenças aparecem entre seus elementos, sendo expresso nas diferentes formas de linguagem. Nesta perspectiva os textos são apropriações singulares deste "universal" no qual são constituídos, o que possibilita serem compartilhados.

Interessa, portanto, na estratégia da desconstrução, explicitar como ele adquiriu sentidos e de forma principal, como adquiriu sentidos que se agregam a específicos conceitos que ganham hegemonia e adquirem uma suposta verdade. Nas palavras de Rodrigues (2009), a leitura desconstrutora serve a dois propósitos: mostrar que a desconstrução acontece no interior dos textos; e discutir como, mesmo na tradição, aparece o jogo do nem/nem, ou seja, a possibilidade de ser isto e aquilo ao mesmo tempo.

Para Continentino (2006, p. 17), "tais são os indecidíveis, ou seja, nem palavras nem conceitos, mas o que Derrida chama de quaseconceitos, pois não obedecem à lógica opositiva dos universais, na medida em que eles se voltam para uma alteridade radical, sem polo de oposição". Os indecidíveis possibilitam problematizar suposições de oposição que percorrem o texto, articulando-se com a desconstrução na medida em que esta se inicia pela evidência de suas contradições e paradoxos. A prática do nem/nem da indecidibilidade remete à noção de alteridade, "de um outro que sempre se faz demonstrar nesse espaçamento, nesses intervalos, nessa distância que se abre entre" (Rodrigues, 2009, p. 51).

Segundo a perspectiva da desconstrução derridiana, o trabalho de problematizar as narrativas produzidas pelas mulheres-mães acerca da sua relação com seus filhos e filhas parte da compreensão de que não existe fundamento ou conceito que seja anterior ou esteja fora do jogo de diferenças que operam em qualquer texto. Além disso, busca problematizar as oposições e os binarismos conforme estes emergem nos textos das entrevistadas (feminino, masculino; homem, mulher; natureza, cultura; razão, afeto; presença, ausência; discurso, prática). Partindo deste referencial, a leitura das entrevistas-textos implicou na "qualidade de diferir, adiar, prorrogar" os sentidos atribuídos aos conceitos, em que "a identidade fixa é substituída pelos efeitos de um processo contínuo de deslocamento" (Rodrigues, 2009, p. 41).

Portanto, segundo Derrida (2001), é importante fazer um gesto duplo, uma escrita redobrada. Isto demanda que, um dos gestos comporte a inversão das hierarquias produzidas pela tradição filosófica e histórica ocidental com o intuito de inverter as posições entre os termos. Neste movimento, é possível visualizar que o termo considerado como derivado ou inferior - o outro - "é essencial à 
compreensão de Si Mesmo, e, em função disso, não pode ser considerado como algo meramente acidental e secundário" (Vasconcelos, 2003, p. 75).

Em um segundo gesto concomitante ao primeiro, é necessário então realizar um deslocamento, enquanto movimento que possibilita a emergência de um "conceito" que não se deixa mais compreender no regime anterior. Nesse momento, há o deslizamento de sentidos, em que os "conceitos" escapam e não podem mais ser fixados. De acordo com Derrida (2001), por esta escrita dupla, estratificada, deslocada e deslocante, há um movimento de inversão que coloca na posição inferior aquilo que estava na posição superior e, em seguida, por meio de um processo de deslocamento que torna impossível fixar identidades, surge um conceito que "não pode mais se marcar senão em um campo textual (...): no limite, é impossível localizá-lo, situálo" (p. 49).

Não há na desconstrução, portanto, o delineamento e a busca por fim anteriormente estabelecido acompanhados do cálculo para a solução de um conflito. Segundo Vasconcelos (2003, p. 76), "na prática da desconstrução, portanto, não se trata de reduzir o exterior ao interior, nem de celebrar anarquicamente o predomínio do conceito de fora sobre o de dentro, mas, a partir dessa oposição, procurar pensar o jogo que a antecede e a torna possível".

A partir desta perspectiva, o trabalho realizado com os textos produzidos envolve descrições arriscadas. Arriscadas porque, por um lado, não se pretende que algumas palavras escritas neste papel possam recobrir qualquer sentido de verdade ou de realidade. São, assim, impressões, gestos, relatos de encontros. Por outro lado, como afirma Derrida, habitamos o contexto do sujeito e do conceito marcados pelas demandas das subjetividades sujeitadas e da metafísica da presença. Assim, espera-se delinear alguns dos fragmentos que, retardando-se, adiando-se, reenviando-se, desviando-se, compuseram os textos das entrevistas.

\section{Dos binarismos às brisuras}

Na problematização realizada por Derrida (2008) sobre o projeto da filosofia calcada na metafísica está incluída a crítica à compreensão de que os sentidos estariam incrustados aos signos. Nesta lógica de pensamento ocidental tradicional o signo seria composto pelo significante e pelo significado, sendo que o significante equivaleria à camada sonora do signo linguístico e o significado à camada abstrata. Isto implica que significante e significado seriam elementos opostos, sendo o significante exterior e o significado interior ao signo. A partir disto, poder-se-ia inferir que a cada significante caberia um único 
significado, exterior e contingencial, derivado e representativo do significante.

Este significado do signo, por sua vez, guardaria proximidade ao logos como phoné, ou seja, preservaria relação direta e privilegiada à presença plena. Seria, portanto, "congênita a esta filosofia" (Derrida, 2009 , p. 413), a organização do pensamento a partir de sistema de oposições, em que opera a ideia de que pares binários encontram-se separados e hierarquicamente colocados, estabelecendo todos os demais sentidos a partir da lógica de compreensão do signo enquanto significante + significado. Assim, a "grande época abrangida pela história da metafísica" (Derrida, 2008, p. 15) está marcada pelo privilégio da razão, da fala, pela concepção de que há um sentido original a ser buscado enquanto essência ou fundamento, implicando que este sentido assuma um caráter de universalidade, ou seja, de verdade que é transparente em si mesma. E é a partir das relações que se estabeleceram e se fixaram entre os pares, por exemplo, natureza e cultura, em que se preservam as características ditas universais dos sentidos que compõe a realidade, que pode ser compreendido o sentido de maternidade e da maternagem vinculado ao feminino.

É pelo discurso possível no âmbito da metafísica, da crença no ser como presença e como substância que ao feminino pôde ser fixamente associada a ideia da ligação "da mulher" com a maternidade, a família e o doméstico, tendo em vista a necessidade de cuidados especiais com seu corpo frágil e seu espírito imperfeito (Del Priore, 2008). Como exemplo, conforme relata Del Priore (2008, p. 83), há relatos sobre o discurso médico predominante no Brasil, entre os séculos XVI e XVIII, destacando o corpo feminino como um "palco obscuro e nebuloso", alimentando a crença de que a natureza feminina, incompreendida, deveria ser controlada e vigiada, e que o corpo da mulher não passaria de um "mecanismo criado por Deus exclusivamente para servir à reprodução".

A maternidade seria o ápice da vida da mulher, sendo também a sua salvação, tendo em vista sua "natureza desviante". Ao ser mãe, a mulher aproximava-se do exemplo de Maria, "a mulher que pariu virgem o salvador do mundo" (Araújo, 2008, p. 52). A constante referência ao corpo da mulher, à biologia como marca irrefutável de sua "natureza frágil" e diferenciadora em oposição à força masculina e à cultura, foi também atribuída pelas entrevistadas como constitutivas das marcas que "caracterizam homens e mulheres". Relata uma das entrevistadas:

"A mulher é muito mais feminina, muito mais atenciosa. Por mais que existem homens assim, quando é adolescente eu acho que eles não descobriram ainda. Eu acho que a característica de gerar filhos, dessa questão da menstruação, 
eu vejo isso em casa que isso é uma coisa bem de verdade, mesmo, é a característica mais forte, é você sangrar, você ser a mulher e você ter um homem, também. Eu acho que é o sexo, a parte sexual, mesmo, é a que mais diferencia. É simples, mas é muito real. Porque em questão de pensamento e atitude em casa, assim, um poderia ser, assim como eles tem essa característica cada um, elas podiam ser inversas, em questão de agitados. Mas a sexual, mesmo, o sexo, de ela ser a menininha, tá agora os peitinhos, as coisinhas. Acho que essa coisa crescendo que é a diferença. Ela ainda tira sarro dele, 'ó a barbinha nascendo'. Sabe? Essa coisa dessa mudança, mesmo, do corpo". (Aimê)

E, ainda:

"Depois que eu fiquei com a Amanda sozinha, a gente parecia duas princesas, de alegria, assim... A menina te traz uma cumplicidade, um ambiente muito mais harmônico dentro da estrutura familiar. Enquanto ela é pequena você até não sente tanto, mas o quanto ela vai crescendo e você vai descansando, o seu corpo. [...] Agora a menina, ela já vai ajudando naturalmente. Sabe? Por mais que ela é bagunceira, ela me dá um alívio. Ela consegue saber o que eu preciso, mais do que ele. Agora, a casa com menino, no meu caso gera sempre uma competitividade, assim de 'eu sou o dono da casa'. A menina não, ela sabe o lugar dela, que a mãe é a rainha, tudo. $O$ menino ele me traz mais conflito, ele tem mais esse negócio do querer, do mandar. Eu acho, que é mais... a casa fica mais pesada". (Aimê)

Esses relatos apontam para identificações do feminino à biologia e ao misticismo. Del Priore (2008, p. 82) aponta como no período colonial, no Brasil, o escasso conhecimento médico sobre o corpo e, em especial, sobre o corpo feminino, contribuía para a mistificação das mulheres. Segundo a autora, "todo conhecimento médico existente sobre o corpo feminino dizia respeito à reprodução" e, especificamente, ao útero, então chamado madre.

Poder-se-ia pensar que, estando inseridas em um tempo histórico atravessado pela crença no feminino como "frágil, imprevisível, submisso, delicado, desconhecido e passivo", o texto da entrevistada produz os corpos e participa nos processos de subjetivação de sua filha meninas a partir da associação destes significados ao signo do feminino? A matriz binária, heterossexual e calcada na essência rege a diferença sexual e se converteu no modelo regulador da sexualidade e da subjetividade. É esta matriz que possibilita aos sujeitos se reconhecerem em referência às suas práticas de 
sexualidade com base na oposição masculino e feminino, heterossexual e homossexual, e na hierarquia entre esses pares. É ela também que possibilita aos sujeitos compreenderem a si mesmos e a outros sob a perspectiva de "referenciais ou representações identitárias".

Sobre este aspecto, Butler (1999, p. 155-156) sugere que um dado sexo "diz respeito, centralmente, à regulação de práticas identificatórias", adquirindo seu efeito naturalizado a partir de práticas repetidas/reiteradas produtoras de alguma sedimentação, em que as camadas insistentemente inseridas neste aspecto do humano criam uma aparência de concretude e coerência. Assim, Butler questiona (1999, p. 163): “a questão não é mais 'como o gênero é constituído como - e através de - uma certa interpretação do sexo' (...), mas, ao invés disso, 'através de que normas regulatórias é o próprio sexo materializado?"

Nos relatos das entrevistadas, há indícios de que, caso algo pareça escapar à ordem imposta, há um chamado para que masculino e feminino voltem a ocupar seus espaços tradicionalmente estabelecidos. Fica explícito o trabalho realizado pelas hierarquias: de um lado, o masculino está atrelado ao que é natural, belo, bom, ativo, completo, substância, perfeito; do outro, feminino se associa à cultura, feio, mau, passivo, incompleto, vazio, imperfeito. Ao feminino cabe a aproximação ao masculino, como possibilidade de ascender a uma posição elevada e de prestígio. Contudo, se há aproximações do masculino ao que é considerado como do âmbito do feminino, isto será encarado como ameaça.

Desvelam-se na metafísica da presença, portanto, as atribuições impressas aos signos da escrita e do feminino, ambos desvalorizados em referência aos seus opostos binários. Em contrapartida, o relato seguinte de uma das entrevistadas aponta um movimento de possíveis deslocamentos dos sentidos tradicionalmente atribuídos ao feminino e que é realizado pela sua filha, quando esta não aceita realizar atividades ditas femininas:

“Pegaram um pouco no pé da Letícia no começo, porque eu sou bailarina clássica, eu tenho anos de balé. E ela odeia balé. E eu tentei, quando ela era pequenininha, colocar no balé, porque minha era mãe bailarina, então todo mundo queria que ela fizesse balé, então 'ah, essa menina não faz balé'. E um dia ela mesma botou um ponto final nessa história, 'eu não gosto de balé, eu não faço balé, eu adoro capoeira e natação’. Então, matou a minha conversa, mas não foi um problema que eu tive que trabalhar com ela, que ela não tava nem aí". (Luiza)

Sobre este aspecto, Derrida (2008) aponta que as contradições existentes em um texto explicitam sua heterogeneidade. Ou seja, 
elas denunciam o fato de que ele é composto não só por elementos produzidos no/pelo trabalho da metafísica, mas ainda pelas/nas possibilidades do devir, contidas nos espaços e linhas de escape que as incoerências comportam.

O trabalho da desconstrução implica, nesta perspectiva, evidenciar contradições e paradoxos do texto e, ainda, decompor binarismos e hierarquias enquanto tentativa de problematizar o sistema de pensamento dominante no qual e a partir do qual o texto foi produzido. A partir da tese do arbitrário do signo de Saussure, Derrida (2008) propõe pensar os sistemas de significação em termos de rastro instituído, ou rastro imotivado. Nesta proposta os signos supõem um sistema diferencial de remissões não podendo ser pensados senão a partir da "retenção da diferença numa estrutura de remessa onde a diferença aparece como tal e permite dessa forma certa liberdade de variação entre os termos plenos" (Derrida, 2008, p. 57). Assim, "o rastro é indefinidamente seu próprio vir-a-serimotivado" (p. 58).

Este vir-a-ser-imotivado do rastro implica que não há significado transcendental do signo e, por conseguinte, que "a escritura é o jogo na linguagem" (Derrida, 2008, p. 61), em que a significação é sempre um devir - enquanto possibilidade de inscrição -, e não mais presença, como o queria a metafísica. Este jogo de remissões permite pensar os conceitos sob rasura, como a marca do apagamento da oposição, abrindo espaço ao movimento da diferença. Esta arquiescritura, ou escritura do rastro, é descrita como "movimento da diferência, arqui-síntese irredutível abrindo ao mesmo tempo uma única e mesma possibilidade a temporalização, a relação ao outro e a linguagem" (Derrida, 2008, p. 73). É por meio dela que se afirma não haver origem absoluta do sentido, visto que "o rastro não é somente a desaparição da origem, ela quer dizer (...) que a origem não desapareceu sequer, que ela jamais foi retroconstituída a não ser por uma não-origem (...)" (p. 75).

Esta escritura marcada pela resistência à substância, à constância e à essência é uma escritura de brisuras, na medida em que há "a impossibilidade para um signo, para a unidade de um significante e de um significado, de produzir-se na plenitude de uma presença e de uma presença absoluta" (Derrida, 2008, p. 85). O deslocamento e o diferimento, enquanto adiamento de possíveis significados aos signos, implicam que haja um espaçamento em que a significação ocorrerá em meio à descontinuidade do tempo e nas brechas, fragmentos e fraturas de um espaço que não se deixa mais compreender na lógica do dentro e do fora.

A possibilidade do deslocamento dos sentidos e do adiamento de uma significação estável e fixa aparece quando, ao ser chamada a ocupar o espaço "reservado ao feminino" na lógica social e familiar, a filha recusa este lugar, insistindo em ocupar e construir outros. Esta 
abertura aparece enquanto possibilidades de devir para a filha, que coloca atributos destinados ao feminino sob rasura, não podendo mais ser pensado a partir da lógica do sentido único.

Porém, seria sua aparição no texto suficiente para romper com a força dos conceitos produzidos pela metafísica? Ou ainda, como encarar e suportar a tensão existente nos textos produzidos pelas mães, que se enunciam e se reconhecem como mulheres, em que aparecem as possibilidades abertas ao feminino, de escapar à atribuição de sentidos verdadeiros e universais, em contrapartida às dificuldades postas ao feminino pela mesma lógica ocidental tradicional?

“E ele, na verdade, as coisas que ele gosta de fazer todo mundo acha o máximo, porque ele surfa, ele anda de skate, e isso que ele surfa desde que ele tem três anos. Então não, esse tipo de situação... às coisas femininas e masculinas, coisas de menino e de menina. Pergunta-se: E se algum deles quisesse fazer alguma atividade, por exemplo, se o Lucas quisesse fazer balé? Não ia fazer. Não. (risos). Não ia fazer (risos), não porque eu não fosse deixar, mas, na verdade, é até feio eu falar isso, mas é porque a gente ia tentar de todas as maneiras com que ele não fizesse, até porque eu conheço o marido que eu tenho. Entendeu? Então eu acho que de todas as maneiras a gente ia, não ia falar 'não, você não vai fazer o balé', a gente ia tentar 'olha, Lucas, o judô é mais legal, o futebol, você joga tão bem futebol', entendeu? Eu acho que não ia rolar, não. Pergunta-se: E se ela quisesse, por exemplo, fazer futebol... Não, daí já, ela faz na educação física, no colégio, numa boa. Eu acho que o problema maior é quando ele quer fazer uma coisa de menina. Ela faz porque assim, ela faz o futebol dela, mas ela vai de shortinho, com faixa na cabeça, bem feminina, sabe? Não tem aquela coisa mulher macho. Então ela adora jogar futebol, adora fazer todos os esportes, faz futebol no colégio, tem a natação que ela adora, faz capoeira que é um esporte que a maioria da turminha dela são meninos, e ela ama a capoeira e a gente estimula, também. Eu acho que ia pegar pesado só se o Lucas fosse querer... lógico, eu não desejo, por exemplo, assim, skate, é uma coisa que eu não gostaria que a Letícia fizesse nunca, porque eles usam aquelas calças lá embaixo, entendeu? Mas se fosse a opção dela, eu não ia... lógico, eu ia também falar 'ah, filha, não é legal, não combina'. Mas acho que o problema ia ser o oposto. Lá em casa eu acho que o estresse ia ser, a gente ia surtar". (Luiza)

Estes últimos trechos das falas-textos indicariam que, por um lado, o deslocamento e o deslizamento de sentidos e significações parecem 
possíveis mais ao feminino do que ao masculino? Por outro, poderíamos pensar, conforme mencionado anteriormente, que a partir da lógica binária e hierárquica, em que se um conceito ou signo ocupa um dos pólos do par, seu deslocamento seria sempre em direção ao seu extremo oposto? Caso o feminino aproxime-se da posição contrária, a ele imediatamente agregar-se-iam os sentidos e qualificações deste oposto? Ou seja, ao aproximar-se do masculino, estaria o feminino aproximando-se de atributos como ativo, positivo, essência, cultura, presença, substância? Em contrapartida, a aproximação do masculino ao feminino traria consigo a justaposição ao passivo, ao vazio, ao negativo, frio, natural e, portanto, desqualificado?

Seguindo a hipótese de uma possível ameaça que rondaria o masculino ao aproximar-se do feminino e, em contraposição, uma provável ascensão do feminino na hierarquia binária quando este se aproxima do masculino, de que forma este movimento pode ser pensado a partir de sua inserção na matriz de pensamento engendrada pela metafísica da presença?

Um primeiro pensamento nos levaria a supor que é justamente porque o deslocamento do feminino se dá em direção ao masculino a partir da lógica opositiva da metafísica da presença - que a ele é possibilitado mover-se, deslizar e afrouxar a fixidez que o prende ao lado desvalorizado da hierarquia. Aproximando-se ao seu oposto, aproximar-se-ia ao falo, à razão, ao princípio e à solidez. De modo semelhante, poderíamos sugerir que, sendo já os atributos destinados ao feminino na filosofia clássica pertencentes à ordem da instabilidade, da inconstância e da maleabilidade, de alguma maneira seria admissível a este feminino escapar, esquivar-se, evadir-se.

Apartada do falo e do logos, seria então aceitável - e até compreensível pelo "bom homem" ocidental - que a mulher buscasse adquirir os predicados tão admiráveis e desejáveis do masculino? Por seus atributos de instabilidade, seria a ela possibilitado esse movimento? Por outro lado, deveria o homem, para dar garantias de seu poder e indiscutível soberania, manter-se afastado de qualquer característica que remeta ao feminino? Adviria daí a fala das mães entrevistadas sobre uma proteção direcionada aos filhos meninos?

“É engraçado, é complicado, porque tem, eu não sei, mas eu acho que a grande maioria das mães de filho homem tem essa coisa da, pelo menos as que eu converso, da proteção com o filho homem". (Luiza)

“(...) todo mundo falava que eu protegia demais ele. Todo mundo falava que 'tudo é o Pedro, você nem olha pra Amanda, você só gosta do Pedro'. (Aimê) 
Haveria um temor por uma possível "perda do falo e do falo do outro"? Por que o masculino deve ser protegido, e protegido pela mãe? Por que é ela, desqualificada e desprovida do falo, da razão e do poder na lógica da tradição filosófica ocidental, quem teme pelo filho? Por que é ela quem deseja protegê-lo? E protegê-lo de que? Que temor e que perigos podem rondá-lo? Teriam os perigos da escrita (secundária e meramente representativa) de tomar o lugar da fala, conforme descreveu Rousseau, relação com uma possível tomada de lugar do masculino pelo feminino?

Vale ressaltar que os aspectos aqui discutidos relacionados ao medo da "perda do pênis" e também às possibilidades de deslocamento dos atributos femininos - mais do que dos masculinos - foram discutidas por Freud (1977) em sua conferência sobre a Feminilidade. Nela, o autor discorre sobre a hipótese de que o homem seria atormentado pela ameaça da castração, enquanto a mulher desejaria o pênis, sendo então acometida por uma inveja do pênis, que "deixará marcas indeléveis em seu desenvolvimento e na formação de seu caráter, não sendo superada, sequer nos casos mais favoráveis, sem um extremo dispêndio de energia psíquica".

Seria então aquilo que se atribui como feminino que aparece deslizando e escapando em direção ao devir, evidenciando que a promessa de um conceito ou sentido universal não é capaz de recobrir o real e dar conta de sua complexidade? Mesmo com reiteradas tentativas de conservar as normas e heteronormas, inclusive aquelas que produzem a separação entre o simbólico e a materialidade dos corpos, as práticas acabam por escapar, por entre fissuras, aos esquemas regulatórios (Butler, 1999). Para Butler (1999, p. 164), é esta mesma instabilidade que abre espaço para "a possibilidade de colocar a consolidação das normas do 'sexo' em crise potencialmente produtiva".

Também Preciado (2002; 2007), em seu manifesto contra-sexual, propõe não mais reconhecer os corpos como de homens ou mulheres, mas como em que não há necessidade de categorização e enumeração. Dessa forma, sugere a renúncia à identidade natural (homem/mulher) ou definições baseadas nas práticas (heterossexuais/homossexuais) para passar a basear--se e a atuar com uma multiplicidade de corpos a partir dos quais a naturalização da diferença sexual pode ser abandonada, abrindo possibilidades à criação da diferença.

A possibilidade de deslocamento dos sentidos e atributos conferidos ao feminino e ao masculino poderia ser pensada, deste modo, como relacionada às possibilidades de devir das práticas subjetivas (e não mais do sujeito-substância), dando espaço às instabilidades e aberturas incessantes. Pensar o "sujeito" a partir do movimento da differánce e, portanto, da arquiescritura, permite pensar em modos de subjetivação que comportam práticas que resistem e transgridem 
a norma. Conforme destaca Derrida (Derrida \& Roudinesco, 2004, p. 68),

o que resiste, e deve resistir a esse determinismo, ou a esse imperialismo do discurso determinista, eu não chamaria nem sujeito, nem eu, nem consciência, nem mesmo inconsciência, mas faria disso um dos lugares do outro, do incalculável, do acontecimento. A singularidade é exposta de fato a este que advém como outro e como incalculável.

A permanente abertura para o devir dos sentidos que se instaura a partir da indecidibilidade e do incalculável não implica, contudo, na busca de uma polissemia dos conceitos. Não se trata das muitas variações de um mesmo tema, algo semelhante a considerar, por exemplo, a possibilidade de existência de "várias identidades" assumidas por um sujeito. Romper com a lógica das identidades, com a lógica do sujeito-substância, do fundamento e da origem é romper também com a ilusão da plenitude e da síntese.

Inserida no pensamento da metafísica da presença, a ideia de polissemia está relacionada ao desdobramento do conceito em seus múltiplos sentidos provenientes de um sentido original. Havendo uma origem de sentido, haveria também uma promessa de retorno a ela, na forma de uma síntese que pudesse recobrir a totalidade do texto. "A polissemia enquanto tal organiza-se no horizonte implícito de uma retomada unitária do sentido (...) que deve permitir a um momento dado (...) voltar a reunir a totalidade de um texto na verdade de seu sentido" (Derrida, 2001, p. 52).

A disseminação, por sua vez, porque inserida na differánce, faz "explodir o horizonte semântico" (Derrida, 2001, p. 51-52). Para o autor, a disseminação "por produzir um número não-finito de efeitos semânticos, não se deixa reconduzir a um presente de origem simples (...). Ela marca uma multiplicidade irredutível e gerativa". Neste movimento de disseminação da escritura não há mais conceitos, mas quase conceitos, chamados também indecidíveis, enquanto unidades de simulacro, que não se deixam mais compreender na oposição binária e que, entretanto, habitam-na, opõe-Ihe resistência, desorganizam-na, mas, sem nunca, constituir um terceiro termo (Derrida, 2001).

Assim, na différance, o movimento de significação só pode ser compreendido a partir dos constantes reenvios e remetimentos dos conceitos a outros tantos que fazem parte do texto em que nenhum está plenamente presente, mas somente deixa rastros. Neste movimento, surgem intervalos que se constituem dinamicamente e que cindem, "como o presente, tudo o que a partir dele se pode pensar, ou seja, todo o ente, na nossa língua metafísica, particularmente a substância e o sujeito" (Derrida, 1991, p. 45). 
A partir das falas-textos produzidas na pesquisa, observa-se, portanto, que as divergências sobre aquilo que se atribui ao feminino e ao masculino denunciam que não é possível encontrar um centro, uma essência, uma substância fundante em si para cada um desses conceitos. Duvidar da possibilidade de que um signo possua apenas um significado presumível remete ao trabalho de crítica ao pensamento da metafísica da presença.

Com esta crítica, o feminino passa a ser posto como indecidível na medida em que, ao denunciar a existência de algo que se poderia pensar como uma operação masculina que busca a verdade, a essência e a identidade, não interessa à mulher (enquanto operação feminina) ocupar uma posição inversa/opositiva na hierarquia, tomando simplesmente o lugar ocupado pelo que foi definido pela tradição como mais importante ou mais exato.

Como indecidível, a mulher é aquela que não acredita na verdade e que, por isso mesmo, abre espaço para um ir além das operações falogocêntricas. Não interessa a ela, portanto, ocupar o lado valorizado de uma hierarquia, mas, tendo em vista que não acredita na busca por uma verdade - já que "a" verdade não existe - o que se busca é, então, transformar a estrutura hierárquica. A partir dos indecidíveis, não seria mais possível pensar em termos de verdade ou não-verdade. Descreve Derrida (1981, p. 62-63)

desde el momento en que la cuestión de la mujer suspende la oposición decidible de lo verdadero y lo no-verdadero, instaura el régimen periódico de las comillas para todos los conceptos pertenecientes al sistema de esta decibilidad filosófica, descalifica el proyecto hermenéutico postulando el sentido verdadero de un texto, libera la lectura del horizonte del sentido del ser o de la verdad del ser, de los valores de producción del producto o de presencia del presente, desde ese momento lo que se desencadena es la cuestión del estilo como cuestión de la escritura, la cuestión de una operación espoleante más poderosa que todo contenido, toda tesis y todo sentido.

É com esta inscrição no jogo das diferenças que os conceitos passam a ser entendidos como quase-conceitos, na medida em que cada um deles é arrastado "em uma cadeia interminável de diferenças, cercando-se ou sobrecarregando-se com uma grande quantidade de precauções, de referências, de notas, de citações, de colagens, de suplementos (...)" (Derrida, 2001, p. 21).

Pensar os conceitos, assim como as experiências dos sujeitos, a partir da différance e dos indecidíveis é, portanto, "entrar no jogo e, sobretudo, no jogo da différance que faz com que nenhuma palavra, nenhum conceito, nenhum enunciado primordial venha sintetizar e 
comandar, a partir da presença teológica de um centro, o movimento e o espaçamento textual das diferenças (Derrida, 2001, p. 21). Nesta lógica de pensamento, suspendem-se as barreiras entre as oposições, visto que se escancaram os diversos reenvios que existem entre eles. Os indecidíveis apontam para a impossibilidade de um signo "ser em si", tendo em vista que é produzido no e pelo sistema de diferenças. Além disso, os indecidíveis não são, nunca, um terceiro termo, como uma promessa de síntese ou restituição de certa ordem.

Nesse jogo, produz-se a disseminação, enquanto produção de sentidos que não se deixam reconduzir a uma origem simples, fraturando o texto e marcando uma multiplicidade de significações que não tem o compromisso de um retorno ou resposta, de uma conclusão, ponto de chegada ou estabelecimento de verdades. Este ir além do pensamento metafísico da presença está, para Derrida, colocado a partir do jogo do nem/nem e da possibilidade de transitar neste "entre" espaços.

Desse modo, essas lacunas existem já no pensamento da metafísica da presença, tendo em vista que nenhum sistema filosófico, assim como a linguagem e o texto, são unidades fechadas. É nessas brechas então que se realiza o movimento de certa liberdade. Portanto, quer cogitemos que o temor apareça quando há indícios da aproximação do masculino e seus atributos ao feminino e suas qualificações, quer conjeturemos que a ameaça esteja no deslocamento que comporta o habitar o entre lugares e consideremos que o perigo está no indecidível e em sua imprevisibilidade, o risco existe desde que prossigamos sedimentando nosso pensamento nas lógicas e compreensões do real decorrentes da metafísica da presença, dos binarismos e hierarquias.

\section{Algumas considerações}

Neste momento nos é viável questionar os limites da filosofia hegemônica calcada na metafísica da presença, suas falhas, contradições e aberturas, explicitando, todavia, a questão de que não é possível permanecer fora deste sistema de pensamento, conforme nos apontou Derrida (2009). Entretanto, é no/por estas brechas que podemos problematizar o sujeito constituído como substância e presença e relevar as possibilidades do devir, bem como, questionar os binarismos, sem abandonar a questão de que a constituição psíquica acontece nessa situação. Ou seja, não abandonamos o fato de que somos constituídos e nos constituímos no tempo social e histórico que produz tanto a possibilidade do devir quanto da subjetividade sujeitada.

$\mathrm{Na}$ senda do conteúdo inconsciente descrito pela psicanálise como aquele que realiza continuamente pressão para tornar-se consciente, 
mas sofre recalque, o movimento da desconstrução está em operação a todo instante. Se há dificuldades em visualizá-lo, encontrá-lo, demarcá-lo, é porque, se nos constituímos no e pelo pensamento da metafísica da presença, com seus binarismos e hierarquias, esta operação tradicional também realiza sua força para manter-se operando. Ela visa de alguma maneira a manutenção da ficção do sujeito da substância, na esperança de oferecer garantias de uma estabilidade - promessa da norma.

Portanto, a escritura como um indecidível não deseja engendrar simplesmente um novo sistema de discurso, mas, no/pelo seu movimento de inversão e deslocamento, lançar os conceitos em um campo textual que é impossível de localizar, de situar. Este duplo movimento demarca uma escrita que é redobrada, uma escrita dupla, deslocada e deslocante, que em seu movimento de afastamento, faz com que os conceitos não sejam mais passíveis de inscrição senão por meio desta "escrita bífida" (Derrida, 2001).

Nesta perspectiva os textos são apropriações singulares deste con(texto) universal no qual são constituídos e compartilhados. Interessa, portanto, na estratégia da desconstrução, não a busca pela "interpretação verdadeira" do texto, mas, antes, explicitar como ele adquiriu sentidos e de forma principal, como adquiriu sentidos que se agregam a específicos conceitos que ganham hegemonia e adquirem uma suposta verdade.

\section{Referências}

Araújo, E. (2008). A arte da sedução: sexualidade feminina na colônia. In Del Priore, M. (Org.). História das mulheres no Brasil (9ạ ed.) (pp. 45-77). São Paulo: Contexto.

Butler, J. (1999). Corpos que pesam: sobre os limites discursivos do 'sexo'. In Louro, G. L. (Org.), O corpo educado: pedagogias da sexualidade. Belo Horizonte: Autêntica.

Butler, J. (2008). Problemas de gênero: feminismo e subversão da identidade ( 2 a ed.). Rio de Janeiro: Civilização Brasileira.

Continentino, A. M. A. (2006). A alteridade no pensamento de Jacques Derrida: Escritura, Meio-Luto, Aporia. Tese de Doutorado, Pontifícia Universidade Católica do Rio de Janeiro, Rio de Janeiro, RJ, Brasil.

Del Priore, M. (2008). Magia e medicina na colônia: o corpo feminino. In Del Priore, M. (Org.), História das mulheres no Brasil (9a ed.) (pp. 78-114). São Paulo: Contexto.

Derrida, J. (1981). Espolones: Los Estilos de Nietzsche. Tradução de M. Arranz Lázaro em Pré-Textos, Valencia.

Derrida, J. (1991). Margens da Filosofia. São Paulo: Papirus.

Derrida, J. (2001). Posições. Belo Horizonte: Autêntica. 
Derrida, J. (2008). Gramatologia. São Paulo: Editora Perspectiva.

Derrida, J. (2009). A escritura e a diferença (4a ed.). São Paulo: Perspectiva.

Derrida, J. \& Roudinesco, E. (2004). De que amanhã: diálogo. Rio de Janeiro: Jorge Zahar.

Foucault, M. (1993). História da sexualidade I: a vontade de saber. Rio de Janeiro: Graal.

Freire Costa, J. (1986). Violência e psicanálise. Rio de Janeiro: Graal.

Freud, S. (1977). Conferência XXXIII - Feminilidade. In Freud, S. Novas conferências introdutórias sobre psicanálise e outros trabalhos. Rio de Janeiro: Imago, vol 22, 139-165. (Original publicado em 1932).

Langaro, F. (2011). (Des)Construções do masculino e do feminino na relação de mulheres-mães com seus filhos e filhas. Dissertação de Mestrado em Psicologia, Universidade Federal de Santa Catarina, Florianópolis, SC, Brasil.

Preciado, B. (2002). Manifiesto contra-sexual, Madrid, Opera Prima.

Preciado, B. (2003). Multitudes queer. Revista Multitudes (online), 12, Recuperado em 10 de outubro de 2015, disponível em http://www. multitudes. net/category/l-edition-papier-enligne/multitudes-12-printemps-2003/

Preciado, B. (2007). Mujeres en los márgenes, Recuperado em 12 de outubro de 2015, disponível em http: //elpais.com/diario/2007/01/13/babelia/1168648750_850 215.html

Rodrigues, C. (2005). Butler e a desconstrução do gênero. Estudos Feministas, 13(1), 179-199.

Rodrigues, C. (2009). Coreografias do feminino. Florianópolis: Mulheres.

Vasconcelos, J. A. (2003). O que é a desconstrução? Revista de Filosofia, 15(17), 73-78.

\section{Endereço para correspondência}

\section{Fabíola Langaro}

Universidade Federal de Santa Catarina

Departamento de Psicologia - Centro de Filosofia e Ciências Humanas

Campus Universitário, Trindade, CEP 88040-500, Florianópolis - SC, Brasil

Endereço eletrônico: flangaro@hotmail.com

\section{Mériti de Souza}

Universidade Federal de Santa Catarina

Departamento de Psicologia - Centro de Filosofia e Ciências Humanas

Campus Universitário, Trindade, CEP 88040-500, Florianópolis - SC, Brasil

Endereço eletrônico: meritisouza@yahoo.com.br

Recebido em: 20/12/2015

Reformulado em: 28/10/2015

Aceito para publicação em: 02/11/2015 


\section{Notas}

* Psicóloga do Centro Hospitalar Unimed Joinville/SC, Docente do Curso de Psicologia da FGG/ACE - Joinville/SC, Brasil. Mestre em Psicologia pela Universidade Federal de Santa Catarina (UFSC).

** Professora na Graduação e no Programa de Pós-Graduação em Psicologia da UFSC - Universidade Federal de Santa Catarina - Florianópolis/SC, Brasil. Doutora em Psicologia Clínica - PUC - SP. Pós Doutorado no CES - Centro de Estudos Sociais da Universidade de Coimbra. 